\title{
Predictive role of perioperative neutrophil to lymphocyte ratio in pediatric congenital heart disease associated with pulmonary arterial hypertension
}

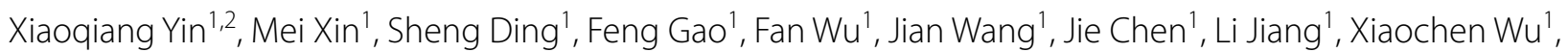
Xianying Wang ${ }^{1,2}$, Jingzhen Liu' ${ }^{1}$ Jinbao Zhang ${ }^{1,2^{*}}$ and Siyi He ${ }^{1 *}$

\begin{abstract}
Background: We aimed to explore the relationship between the neutrophil to lymphocyte ratio (NLR) and the early clinical outcomes in children with congenital heart disease (CHD) associated with pulmonary arterial hypertension (PAH) after cardiac surgery.

Methods: A retrospective observational study involving 190 children from January 2013 to August 2019 was conducted. Perioperative clinical and biochemical data were collected.

Results: We found that pre-operative NLR was significantly correlated with AST, STB, CR and UA $(P<0.05)$, while post-operative NLR was significantly correlated with ALT, AST, BUN $(P<0.05)$. Increased post-operative neutrophil count and NLR as well as decreased lymphocyte count could be observed after cardiac surgery $(P<0.05)$. Level of pre-operative NLR was significantly correlated with mechanical ventilation time, ICU stay time and total length of stay $(P<0.05)$, while level of post-operative NLR was only significantly correlated to the first two $(P<0.05)$. By using ROC curve analysis, relevant areas under the curve for predicting prolonged mechanical ventilation time beyond $24 \mathrm{~h}, 48 \mathrm{~h}$ and $72 \mathrm{~h}$ by NLR were statistically significant $(P<0.05)$.
\end{abstract}

Conclusion: For patients with CHD-PAH, NLR was closely related to early post-operative complications and clinical outcomes, and could act as a novel marker to predict the occurrence of prolonged mechanical ventilation.

Keywords: Neutrophil to lymphocyte ratio, Congenital heart disease associated with pulmonary arterial hypertension, Children, Cardiac surgery, Correlation

\section{Background}

Congenital heart disease (CHD) associated with pulmonary arterial hypertension (PAH) refers to the increase of pulmonary artery pressure caused by CHD with shunt from systemic circulation to pulmonary circulation. PAH

\footnotetext{
*Correspondence: jinbaozhang001@163.com; hesiyi@vip.163.com

${ }^{1}$ Department of Cardiovascular Surgery, Jinniu District, General Hospital of Western Theater Command, Rongdu Avenue No.270, Chengdu 610083, Sichuan, China

Full list of author information is available at the end of the article
}

can occur at various stages in the evolution of CHD, and the degree of pulmonary vascular disease is regarded as a key factor affecting the efficacy and timing of surgery. Most CHD operations need to be completed at an early age. However, multiple organs are not fully developed in childhood, thus leading to high mortality and poor clinical prognosis. In addition, the inflammatory reaction induced by cardiopulmonary bypass (CPB) will influence the post-operative pulmonary and cardiovascular function and reduce the long-term survival rate of patients. 
It is reported that the systemic inflammatory response syndrome after $\mathrm{CPB}$ in children resulted in prolonged mechanical ventilation time, ICU stay time as well as total hospitalization duration [1]. Therefore, for patients with CHD, it is of great significance to explore effective clinical indicators in the early stage after $\mathrm{CPB}$ cardiac surgery to evaluate the level of inflammatory response.

Recently, a variety of studies have shown that inflammatory markers are closely related to the clinical outcomes of many cardiovascular diseases [2-4]. The neutrophil to lymphocyte ratio (NLR) has been paid more attention on due to its significant features of low price, immediate access and repeatable detection. Numerous evidences suggest that NLR is a novel marker which can reflect the level of systematic inflammation. As for cardiovascular events, NLR is also a remarkable predictive index. Recent studies perceived that the higher pre-operative NLR in children with CHD was not only associated with a higher risk for low cardiac output in the early post-operative period but also correlated with mortality [5-7]. Besides, Xu et al. found that post-operative NLR in pediatric patients with CHD after CPB was significantly higher than those before operation, which was consistent with increased mechanical ventilation time and intensive care unit (ICU) stay time [8].

Although NLR is a valuable indicator for inflammation, there is limited evidence in the literature of children with CHD-PAH. Therefore, the present research intends (1) to explore the correlation between NLR levels and early clinical outcomes in children with CHD-PAH undergoing $\mathrm{CPB}$ open heart surgery and (2) to evaluate the reliability of NLR level as a predictor for prolongation of mechanical ventilation time, thereby providing underlying predictor for clinical prognosis.

\section{Methods}

\section{Subjects}

This was a retrospective observational study conducted in the Department of Cardiac surgery of General Hospital of Western Theater Command from January 2013 to August 2019. Inclusion criteria: (a) consecutive patients less than 14 years old in our department; (b) according to 2015 guidelines by the European Society of Cardiology (ESC) and the European Respiratory Society (ERS) [9], the estimation of pulmonary arterial systolic pressure (PASP) is based on the peak tricuspid regurgitation velocity and right atrial pressure by echocardiography, and all patients were diagnosed with $\mathrm{PAH}$ when PASP was greater than $40 \mathrm{mmHg}$; (c) open heart surgery with $\mathrm{CPB}$ was performed. Exclusion criteria: (a) redo-surgery; (b) patient was diagnosed with any type of infection by clinical symptoms, signs and related examinations after admission; (c) patients received antibiotics therapy before operation; (d) patients received endotracheal intubation before surgery. The study was reviewed and approved by the Ethics Committee of General Hospital of Western Theater Command (No. 2020ky003). The informed consent form was given and signed by all guardians of the children. All methods were carried out in accordance with the ethical standards in the Declaration of Helsinki.

\section{Data collection}

Perioperative clinical and biochemical data were collected retrospectively through the clinical electronic medical record system of our hospital. The clinical data included patient demographics (gender, age, weight, diagnosis), PASP, the Risk Adjustment in Congenital Heart Surgery version 1 (RACHS-1) score, CPB time, aortic clamping time, operation time, and follow-up clinical outcomes after surgical procedure including mechanical ventilation time, ICU stay time and total length of stay. On the morning of the first day after admission, peripheral venous blood was taken and sent to the laboratory department of our hospital for blood routine examination, and pre-operative NLR was calculated. After CPB cardiac surgery, peripheral venous blood was taken from the patients in the early morning of the first day in the ICU and sent to the laboratory of our hospital. The biochemical data included blood routine related indexes (neutrophil count, lymphocyte count and the calculated post-operative NLR), liver function related indicators (glutamic pyruvic transaminase, glutamic oxaloacetic transaminase, albumin and total bilirubin), renal function related indicators (creatinine, urea nitrogen, uric acid). The LVEF recorded by echocardiography was collected before discharge.

\section{Statistical analysis}

All data were analyzed by SPSS25. Kolmogorov Smirnov test was used to evaluate the normal distribution of variables. The measurement data that approximate or conform to the normal distribution were expressed as mean \pm standard deviation, while those that do not conform to normal distribution were expressed as median (quartile interval). The enumeration data were expressed as the corresponding number of cases. Two independent samples Mann-Whitney U test was used for comparison between groups. Spearman correlation analysis was used to evaluate the correlation between NLR and various Indexes. ROC curves were used to examine the various cutoff values of pre-operative and post-operative NLR to predict the need for mechanical ventilation beyond $24 \mathrm{~h}, 48 \mathrm{~h}$ and $72 \mathrm{~h}$ respectively. All tests were performed 2-tailed, with $\mathrm{P}<0.05$ considered statistically significant. 


\section{Results}

\section{Baseline characteristics}

A total of 190 patients experienced CPB, including 104 males $(54.7 \%)$ and 86 females $(45.3 \%)$. The median age was $18.383(7.367-49.367)$ months, and the median weight was $9.25(6.5-15) \mathrm{kg}$. The median pre-operative PASP was $75(67.75-82) \mathrm{mmHg} .135$ patients were diagnosed as simple CHD, while 55 patients were diagnosed as complex $\mathrm{CHD}$, which were minutely described in Additional file 1: Table S1. The results of RACHS-1 score was as follows: RACHS-1 $(n=12)$, RACHS-2 $(\mathrm{n}=131)$, RACHS-3 $(\mathrm{n}=44)$, RACHS $-4 \quad(\mathrm{n}=1)$ and RACHS-5 $(n=2)$. All patients received mechanical ventilation for 22.4 (5.917-47.596) hours, stayed in ICU after surgery for 2.856 (0.917-5.864) days, and had a total length of stay for 18 (14-24.25) days. Detailed information was shown in Table 1.

Correlation between NLR and perioperative characteristics First of all, we analyzed the correlation between preoperative NLR and perioperative indexes of cardiac surgery. As shown in Table 2, pre-operative NLR was significantly correlated with AST, STB, CR and UA after operation $(\mathrm{P}<0.05)$. However, there was no significant relationship between pre-operative NLR and PASP $(\mathrm{P}=0.134), \mathrm{CPB}$ time $(\mathrm{P}=0.578)$, aortic clamping time $(\mathrm{P}=0.547)$, operation time $(\mathrm{P}=0.572)$, post-operative NLR $(\mathrm{P}=0.212)$, ALT $(\mathrm{P}=0.558)$, ALB $(\mathrm{P}=0.14)$, BUN $(\mathrm{P}=0.194)$ and $\operatorname{LVEF}(\mathrm{P}=0.268)$.

Secondly, we explored the pertinence between postoperative NLR and liver function, renal function and LVEF after cardiac surgery. The results revealed that post-operative NLR was significantly correlated with ALT, AST and BUN after operation $(\mathrm{P}<0.05)$ (Table 3$)$. No significant correlation could be observed between post-operative NLR and post-operative neutrophil count $(\mathrm{P}=0.054)$, post-operative lymphocyte count $(\mathrm{P}=0.224), \quad$ ALB $\quad(\mathrm{P}=0.183), \quad \mathrm{STB} \quad(\mathrm{P}=0.125), \quad \mathrm{CR}$ $(\mathrm{P}=0.087)$, UA $(\mathrm{P}=0.162), \operatorname{LVEF}(\mathrm{P}=0.605)$.

\section{Comparison of perioperative neutrophil count, lymphocyte count and NLR}

Due to inflammatory responses caused by $\mathrm{CPB}$, postoperative neutrophil count at the 1st day after surgery was significantly increased compared with pre-operative corresponding level $(\mathrm{P}<0.05)$, while the postoperative lymphocyte count was significantly decreased $(\mathrm{P}<0.05)$. The median pre-operative NLR was 0.586 (0.404-1.022), which markedly increased to 6.499 (4.897-9.114) post-operatively $(\mathrm{P}<0.05)$ (Table 4$)$.
Table 1 Baseline characteristics of included patients

\begin{tabular}{|c|c|}
\hline Variable & Results \\
\hline \multicolumn{2}{|l|}{ Pre-operative } \\
\hline Male/female & 104/86 \\
\hline Age (months) & $18.383(7.367-49.367)$ \\
\hline Weight (kg) & $9.250(6.500-15.000)$ \\
\hline PASP $(m m H g)$ & $75.000(67.750-82.000)$ \\
\hline \multicolumn{2}{|l|}{ Diagnosis } \\
\hline Simple CHD & 78 \\
\hline Complex CHD & 112 \\
\hline \multicolumn{2}{|l|}{ RACHS-1 score } \\
\hline 1 & 12 \\
\hline 2 & 131 \\
\hline 3 & 44 \\
\hline 4 & 1 \\
\hline 5 & 2 \\
\hline Pre-operative neutrophil $\left(10^{9} / \mathrm{L}\right)$ & $2.595(1.998-3.553)$ \\
\hline Pre-operative lymphocyte $\left(10^{9} / \mathrm{L}\right)$ & $4.625(3.008-5.848)$ \\
\hline Pre-operative NLR & $0.586(0.404-1.022)$ \\
\hline \multicolumn{2}{|l|}{ Intra-operative } \\
\hline CPB time (min) & $61.000(52.000-72.000)$ \\
\hline Aortic clamping time (min) & $34.000(26.750-47.000)$ \\
\hline Operation time (min) & $140.000(130.000-160.000)$ \\
\hline \multicolumn{2}{|l|}{ Post-operative } \\
\hline Post-operative neutrophil $\left(10^{9} / \mathrm{L}\right)$ & $9.660(7.860-12.190)$ \\
\hline Post-operative lymphocyte $\left(10^{9} / \mathrm{L}\right)$ & $1.490(1.090-1.873)$ \\
\hline Post-operative NLR & $6.499(4.897-9.114)$ \\
\hline $\operatorname{ALT}(U / L)$ & $20.550(17.400-26.800)$ \\
\hline AST (U/L) & $105.400(80.625-133.85)$ \\
\hline ALB $(g / L)$ & $42.203 \pm 3.714$ \\
\hline $\mathrm{STB}(\mu \mathrm{mol} / \mathrm{L})$ & $21.370(15.868-30.125)$ \\
\hline $\mathrm{CR}(\mu \mathrm{mol} / \mathrm{L})$ & $28.800(23.000-35.000)$ \\
\hline $\mathrm{BUN}(\mathrm{mmol} / \mathrm{L})$ & $6.690(5.365-7.903)$ \\
\hline $\mathrm{UA}(\mu \mathrm{mol} / \mathrm{L})$ & $312.650(251.075-419.025)$ \\
\hline $\operatorname{LVEF}(\%)$ & $60.000(58.000-62.000)$ \\
\hline Mechanical ventilation time (h) & $22.400(5.917-47.596)$ \\
\hline ICU stay time (days) & $2.856(0.917-5.864)$ \\
\hline Total length of stay (days) & $18.000(14.000-24.250)$ \\
\hline \multicolumn{2}{|c|}{$\begin{array}{l}\text { PASP: pulmonary arterial systolic pressure; CHD: congenital heart disease; } \\
\text { RACHS-1: risk Adjustment for Congenital Heart Surgery-1;NLR: neutrophil } \\
\text { to lymphocyte ratio; CPB: cardiopulmonary bypass;ALT: glutamic pyruvic } \\
\text { transaminase; AST: glutamic oxaloacetic transaminase; ALB: albumin; STB: Serum } \\
\text { total bilirubin; CR: creatinine; BUN: blood urea nitrogen; UA: uric acid; LVEF: Left } \\
\text { ventricular ejection fraction; ICU: intensive care unit }\end{array}$} \\
\hline
\end{tabular}

\section{Correlation between NLR and clinical outcomes}

As presented in Table 5, pre-operative NLR was significantly correlated with mechanical ventilation time, ICU stay time and total length of stay $(\mathrm{P}<0.05)$. Post-operative NLR was closely related to mechanical ventilation time and ICU stay time $(\mathrm{P}<0.05)$, but had no obvious correlation with total length of stay $(\mathrm{P}=0.161)$. 


\begin{tabular}{|c|c|c|}
\hline Variable & Coefficient & P-value \\
\hline PASP (mmHg) & -0.109 & 0.134 \\
\hline CPB time (min) & -0.040 & 0.578 \\
\hline Cross-clamping time (min) & 0.044 & 0.547 \\
\hline Operation time (min) & 0.041 & 0.572 \\
\hline Post-operative NLR & -0.091 & 0.212 \\
\hline $\mathrm{ALT}(U / \mathrm{L})$ & -0.043 & 0.558 \\
\hline AST (U/L) & -0.252 & $0.000^{* *}$ \\
\hline ALB (g/L) & -0.107 & 0.140 \\
\hline STB (umol/L) & -0.242 & $0.001^{* *}$ \\
\hline CR (umol/L) & 0.166 & $0.022^{*}$ \\
\hline BUN (mmpl/L) & -0.095 & 0.194 \\
\hline UA (umol/L) & -0.174 & $0.016^{*}$ \\
\hline LVEF (\%) & 0.081 & 0.268 \\
\hline
\end{tabular}

* Indicates significant correlation at level 0.05

** Indicates significant correlation at level 0.01

Table 3 Correlation analysis of post-operative NLR with post-operative indicators

\begin{tabular}{lcl}
\hline Variable & Coefficient & P-value \\
\hline Post-operative neutrophil $\left(10^{9} / \mathrm{L}\right)$ & -0.140 & 0.054 \\
Post-operative lymphocyte $\left(10^{9} / \mathrm{L}\right)$ & -0.089 & 0.224 \\
ALT $(\mathrm{U} / \mathrm{L})$ & 0.213 & $0.003^{* *}$ \\
AST $(\mathrm{U} / \mathrm{L})$ & 0.165 & $0.023^{*}$ \\
ALB $(\mathrm{g} / \mathrm{L})$ & 0.097 & 0.183 \\
STB (umol/L) & 0.112 & 0.125 \\
CR (umol/L) & -0.125 & 0.087 \\
BUN (mmpl/L) & 0.264 & $0.000^{* *}$ \\
UA (umol/L) & 0.102 & 0.162 \\
LVEF (\%) & 0.038 & 0.605
\end{tabular}

* Indicates significant correlation at level 0.05

** Indicates significant correlation at level 0.01

Table 4 Comparison of perioperative neutrophil count, lymphocyte count and NLR

\begin{tabular}{llll}
\hline Variable & Pre-operation & Post-operation & P-value \\
\hline Neutrophil & $2.595(1.998-3.553)$ & $9.660(7.860-12.190)$ & $0.000^{* *}$ \\
Lymphocyte & $4.625(3.008-5.848)$ & $1.490(1.090-1.873)$ & $0.000^{* *}$ \\
NLR & $0.586(0.404-1.022)$ & $6.499(4.897-9.114)$ & $0.000^{* *}$ \\
\hline
\end{tabular}

** Indicates rank sum test at level 0.01

\section{Predictive value of NLR for prolonged mechanical} ventilation

At first, pre-operative NLR was studied for the value in predicting the prolongation of mechanical ventilation. The corresponding sensitivity and specificity of
Table 5 Correlation between NLR and clinical outcomes

\begin{tabular}{|c|c|c|c|c|}
\hline \multirow[t]{2}{*}{ Variable } & \multicolumn{2}{|c|}{ Pre-operative NLR } & \multicolumn{2}{|c|}{ Post-operative NLR } \\
\hline & Coefficient & P-value & Coefficient & P-value \\
\hline $\begin{array}{l}\text { Mechanical ventilation } \\
\text { time }\end{array}$ & -0.156 & $0.032^{*}$ & 0.361 & $0.000^{* *}$ \\
\hline ICU stay time & -0.227 & $0.002^{* *}$ & 0.168 & $0.020^{*}$ \\
\hline Total length of stay & -0.171 & $0.018^{*}$ & 0.102 & 0.161 \\
\hline
\end{tabular}

pre-operative NLR predicting mechanical ventilation time beyond $24 \mathrm{~h}, 48 \mathrm{~h}$ and $72 \mathrm{~h}$ respectively, as well as the best cutting point of pre-operative NLR, were shown in Fig. 1a. Subsequently, we analyzed the reliability of post-operative NLR in predicting the prolongation of mechanical ventilation time. The relevant sensitivity and specificity of post-operative NLR predicting mechanical ventilation time over $24 \mathrm{~h}, 48 \mathrm{~h}$ and $72 \mathrm{~h}$ respectively, as well as the best cutting point of post-operative NLR, were demonstrated in Fig. 1b. The areas under the ROC curve of NLR predicting mechanical ventilation time extension $24 \mathrm{~h}, 48 \mathrm{~h}$ and $72 \mathrm{~h}$ were statistically significant $(\mathrm{P}<0.05)$.

\section{Discussion}

CHD-PAH belongs to the first category in the classification of pulmonary hypertension and is a common complication of CHD with left to right shunt. Once it occurs, it will greatly increase the risk for CHD surgery. Therefore, early surgical repair of defects is deemed as a significant way to correct PAH thoroughly. However, the systemic inflammatory response caused by $\mathrm{CPB}$ with open heart surgery seemed to associate with high frequency of post-operative neuromotor disabilities [10]. A prospective cohort study suggested that neutrophil phenotypic was regarded to be correlated with post-operative acute kidney injury in infants undergoing $\mathrm{CPB}$ and could be used to predict inflammatory organ dysfunction [11]. The results of our study also confirmed that the level of inflammation in children with CHD-PAH significantly increased after $\mathrm{CPB}$ open heart surgery.

Recently, many studies have revealed the role of hematological parameters in predicting the prognosis of patients with CHD, including BNP, N-terminal probrain natriuretic peptide (NT-proBNP) $[12,13]$, serum troponin [14], C-reactive protein (CRP) [15], Red blood cell distribution width (RDW) [16], NLR and so on. NLR reflects not only the balance between neutrophil count and lymphocyte count but also the degree of systemic inflammation, and is related to the severity degree of cardiovascular disease. Previous studies have found that NLR was considered to predict the worsening of the renal function in diabetic patients [17]. In a prospective 


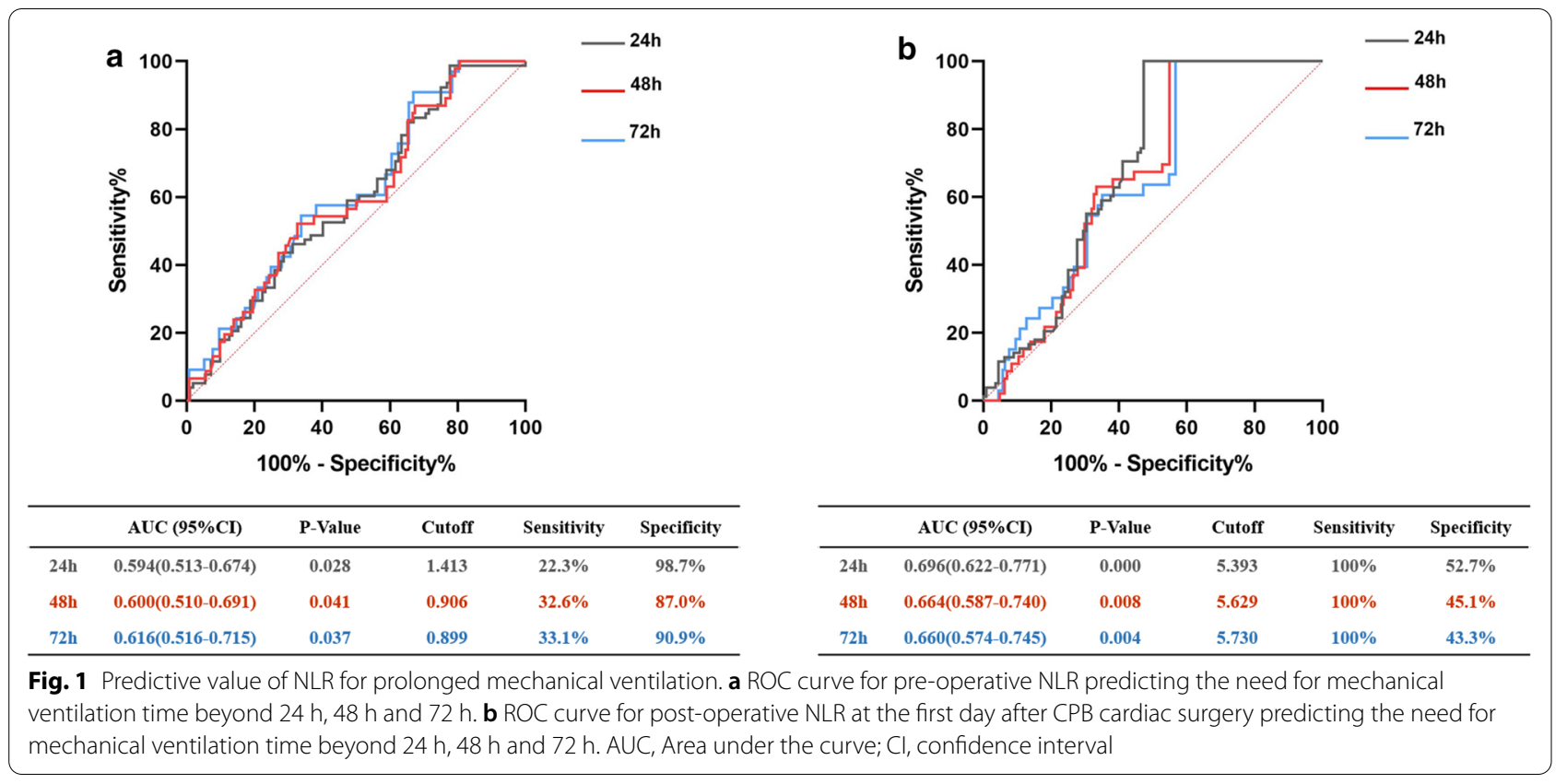

multicenter cohort study, Ackland et al. suggested that pre-operative NLR greater than 4 was associated with perioperative myocardial injury and systemic inflammation might contribute to the development of perioperative myocardial injury [18]. Existing data suggested that NLR could be used as a marker for risk assessment in patients with acute [19] and chronic [20] heart failure, and was closely associated with increased all-cause mortality [21]. Recently, many studies emphasized that inflammation was involved in the formation of pulmonary hypertension. In children with CHD, especially with continuous left-to-right shunt, pulmonary blood flow and pressure increase, resulting in pulmonary artery endothelial cell dysfunction and pulmonary vascular remodeling. Mechanical stimulation of pulmonary vascular wall by continuous left-to-right shunt lead to inflammatory response of pulmonary vascular wall. Pulmonary vascular endothelial cells over-released vasoconstrictive factors such as endothelin, causing pulmonary vasoconstriction, thus resulting in increased pulmonary arterial pressure and eventually pulmonary hypertension [22]. In the present study, we firstly applied NLR as a predictive factor in pediatric patients with CHD-PAH undergoing cardiac surgery. Our results indicated that NLR was closely correlated with early post-operative complications of liver and kidney function as well as poor clinical outcomes.

At present, there are few reports on the relationship between NLR and the prognosis of children with CHD$\mathrm{PAH}$. Therefore, this study further evaluated the predictive value of NLR for the prolongation of mechanical ventilation time. Prolonged mechanical ventilation time is one of the most important outcome indicators for cardiac surgery. Once it occurs, it may lead to pulmonary edema, atelectasis and ventilator-associated pneumonia, which would further exacerbate the illness state of the children [23]. The longer duration of mechanical ventilation could result in a significant increase in mortality [24]. Faruk et al. reported that NLR was capable of predicting successful extubation following prolonged intubation in patients [25]. In the present research, we discovered that the areas under the curve of $24 \mathrm{~h}, 48 \mathrm{~h}$ and $72 \mathrm{~h}$ prolonged mechanical ventilation predicted by NLR before and after operation were statistically significant. Furthermore, it was observed that pre-NLR had high specificity and post-NLR had high sensitivity in predicting prolonged mechanical ventilation, suggesting that monitoring the level of NLR in children with CHD-PAH was helpful to perceive the occurrence of post-operative adverse events such as prolonged mechanical ventilation. Consequently, more attention should be focused on children with elevated NLR before and early after surgery, and effective interventions should be timely carried out to prevent the occurrence of adverse events. For example, patients in high risk before operation can be treated with oxygen inhalation, improvement of cardiac function and reduction of pulmonary artery pressure by using of targeted drugs. After operation, effective measures for prevention low cardiac output syndrome, acute lung injury and ventilator-associated pneumonia are beneficial for successful weaning. Besides, early respiratory rehabilitation exercise was considered to be advantageous 
for patients with mechanical ventilation [26] so as to improve the clinical prognosis of children.

There are still several limitations of the present study that may provide further extension of the research. Firstly, the PASP of the children with CHD-PAH was measured by echocardiography, which was not much accurate compared with the right cardiac catheterization. Secondly, this study was designed retrospectively in a single center with a small sample size. Finally, longer follow-up is needed to predict the effect of NLR on the long-term prognosis of patients.

\section{Conclusion}

In conclusion, pre-operative and post-operative NLR in children with CHD-PAH were closely related to early postoperative complications and clinical outcomes and could predict the occurrence of prolonged mechanical ventilation time to some extent. As a new type of inflammatory marker, NLR is simple, cost-effective and easy to be obtained, thus having great advantages while used in community and primary medical institutions. Based on the present study, we suppose that dynamic monitoring of NLR is beneficial for improving the clinical outcomes of children with CHD-PAH after cardiac surgery.

\section{Supplementary Information}

The online version contains supplementary material available at https://doi. org/10.1186/s12893-020-01009-x.

Additional file 1: Supplementary Table 1. Detailed diagnosis of included patients.

\begin{abstract}
Abbreviations
NLR: Neutrophil to lymphocyte ratio; CHD: Congenital heart disease; PAH: Pulmonary arterial hypertension; CPB: Cardiopulmonary bypass; ICU: Intensive care unit; ROC: Receiver operating characteristic; PASP: Pulmonary arterial systolic pressure; ASD: Atrial septal defect; VSD: Ventricular septal defect; PDA: Patent ductus arteriosus; ALT: Glutamic pyruvic transaminase; AST: Glutamic oxaloacetic transaminase; ALB: Albumin; STB: Serum total bilirubin; CR: Creatinine; BUN: Blood urea nitrogen; UA: Uric acid; RACHS-1: Risk adjustment for congenital heart surgery-1; LVEF: Left ventricular ejection fraction.
\end{abstract}

\section{Acknowledgements}

Not applicable.

\section{Authors' contributions}

XY performed the statistical analysis and wrote the manuscript. MX, SD and FG collected the clinical data. FW, JW and JC collected the biochemical data. JL, XW1, XW2 and LJ performed the statistical analysis and drew tables. SH and JZ designed the study, gave final approval of the version to be published. All authors read and approved the final manuscript.

\section{Funding}

The present work was supported by the National Natural Science Foundation of China (No. 81700277) and the National Key Research and Development Project (417311 JW). The funders had no role in the design of the study and collection, analysis, and interpretation of data and in writing the manuscript.

\section{Availability of data and materials}

The datasets used and/or analysed during the current study are available from the corresponding author on reasonable request.

\section{Ethics approval and consent to participate}

The study was reviewed and approved by the Ethics Committee of General Hospital of Western Theater Command (No. 2020ky003). The informed consent form was given and signed by all guardians of the children. All methods were carried out in accordance with the ethical standards in the Declaration of Helsinki.

\section{Consent for publication}

Not applicable.

\section{Competing interests}

Authors have nothing to disclose with regard to commercial support.

\section{Author details}

${ }^{1}$ Department of Cardiovascular Surgery, Jinniu District, General Hospital of Western Theater Command, Rongdu Avenue No.270, Chengdu 610083, Sichuan, China. ${ }^{2}$ North Sichuan Medical College, Nanchong, Sichuan, China.

Received: 18 July 2020 Accepted: 13 December 2020

Published online: 04 January 2021

\section{References}

1. Soares LC, Ribas D, Spring R, Silva JM, Miyague NI. Clinical profile of systemic inflammatory response after pediatric cardiac surgery with cardiopulmonary bypass. Arq Bras Cardiol. 2010;94(1):127-33.

2. Sreejit G, Abdel-Latif A, Athmanathan B, Annabathula R, Dhyani A, Noothi SK, Quaife-Ryan GA, Al-Sharea A, Pernes G, Dragoljevic D, et al. Neutrophil-derived S100A8/A9 amplify granulopoiesis following myocardial infarction. Circulation. 2020;2:099.

3. Kittel-Schneider S, Kaspar M, Berliner D, Weber H, Deckert J, Ertl G, Störk S, Angermann C, Reif A. CRP genetic variants are associated with mortality and depressive symptoms in chronic heart failure patients. Brain Behav Immun. 2018;71:133-41.

4. Adamsson Eryd S, Borné Y, Melander O, Persson M, Smith JG, Hedblad $B$, Engström G. Red blood cell distribution width is associated with incidence of atrial fibrillation. J Intern Med. 2014;275(1):84-92.

5. Iliopoulos I, Alder MN, Cooper DS, Villarreal EG, Loomba R, Sahay RD, Fei $\mathrm{L}$, Steele PE, Flores S. Pre-operative neutrophil-lymphocyte ratio predicts low cardiac output in children after cardiac surgery. Cardiol Young. 2020;30(4):521-5.

6. Manuel V, Miana LA, Guerreiro GP, Tenorio DF, Turquetto A, Penha JG, Massoti MR, Tanamati C, Junior APF, Caneo LF, et al. Prognostic value of the preoperative neutrophil-lymphocyte ratio in patients undergoing the bidirectional Glenn procedure. J Card Surg. 2020;35(2):328-34.

7. Savluk OF, Guzelmeric F, Yavuz Y, Ukil F, Yilmaz A, Cevirme D, Tuncer E, Hatemi AC, Ceyran H. Neutrophil-lymphocyte ratio as a mortality predictor for Norwood stage I operations. Gen Thorac Cardiovasc Surg. 2019;67(8):669-76.

8. Xu H, Sun Y, Zhang S. The relationship between neutrophil to lymphocyte ratio and clinical outcome in pediatric patients after cardiopulmonary bypass surgery: a retrospective study. Front Pediatr. 2019;7:308.

9. Galie N, Humbert M, Vachiery JL, Gibbs S, Lang I, Torbicki A, Simonneau G, Peacock A, Vonk Noordegraaf A, Beghetti M, et al. 2015 ESC/ERS Guidelines for the diagnosis and treatment of pulmonary hypertension: The Joint Task Force for the Diagnosis and Treatment of Pulmonary Hypertension of the European Society of Cardiology (ESC) and the European Respiratory Society (ERS): Endorsed by: Association for European Paediatric and Congenital Cardiology (AEPC), International Society for Heart and Lung Transplantation (ISHLT). Eur Heart J. 2016;37(1):67-119.

10. Gessler P, Schmitt B, Prètre R, Latal B. Inflammatory response and neurodevelopmental outcome after open-heart surgery in children. Pediatr Cardiol. 2009;30(3):301-5.

11. Huber JN, Hilkin BM, Hook JS, Brophy PD, Davenport TL, Davis JE, Colaizy TT, Moreland JG. Neutrophil phenotype correlates with postoperative 
inflammatory outcomes in infants undergoing cardiopulmonary bypass. Pediatr Crit Care Med. 2017;18(12):1145-52.

12. Qu J, Liang H, Zhou N, Li L, Wang Y, Li J, Cui Y. Perioperative NT-proBNP level: potential prognostic markers in children undergoing congenital heart disease surgery. J Thorac Cardiovasc Surg. 2017;154(2):631-40.

13. Cantinotti M, Law Y, Vittorini S, Crocetti M, Marco M, Murzi B, Clerico A. The potential and limitations of plasma BNP measurement in the diagnosis, prognosis, and management of children with heart failure due to congenital cardiac disease: an update. Heart Fail Rev. 2014;19(6):727-42.

14. Kowalik E, Klisiewicz A, Rybicka J, Biernacka EK, Hoffman P. High sensitivity cardiac troponin $T$ and systemic right ventricular function in adults with congenitally corrected transposition of the great arteries. Int J Cardiol. 2017;241:168-72.

15. Scognamiglio G, Kempny A, Price LC, Alonso-Gonzalez R, Marino P, Swan L, Alto M, Hooper J, Gatzoulis MA, Dimopoulos K, et al. C-reactive protein in adults with pulmonary arterial hypertension associated with congenital heart disease and its prognostic value. Heart. 2014;100(17):1335-41.

16. Polat V, Iscan S, Etli M, El Kilic H, Gürsu O, Eker E, Ozdemir F. Red cell distribution width as a prognostic indicator in pediatric heart disease and after surgery. Biomed Res Int. 2014:2014:681679.

17. Azab B, Daoud J, Naeem FB, Nasr R, Ross J, Ghimire P, Siddiqui A, Azzi N, Rihana N, Abdallah M, et al. Neutrophil-to-lymphocyte ratio as a predictor of worsening renal function in diabetic patients (3-year follow-up study). Ren Fail. 2012;34(5):571-6.

18. Ackland GL, Abbott TEF, Cain D, Edwards MR, Sultan P, Karmali SN, Fowler AJ, Whittle JR, MacDonald NJ, Reyes A, et al. Preoperative systemic inflammation and perioperative myocardial injury: prospective observational multicentre cohort study of patients undergoing non-cardiac surgery. $\mathrm{Br}$ J Anaesth. 2019;122(2):180-7.

19. Cho JH, Cho HJ, Lee HY, Ki YJ, Jeon ES, Hwang KK, Chae SC, Baek SH, Kang SM, Choi DJ, et al. Neutrophil-lymphocyte ratio in patients with acute heart failure predicts in-hospital and long-term mortality. J Clin Med. 2020;9:2.
20. Yan W, Liu C, Li R, Mu Y, Jia Q, He K. Usefulness of the neutrophil-tolymphocyte ratio in predicting adverse events in elderly patients with chronic heart failure. Int Heart J. 2016:57(5):615-21.

21. Kim S, Eliot M, Koestler DC, Wu WC, Kelsey KT. Association of neutrophilto-lymphocyte ratio with mortality and cardiovascular disease in the jackson Heart Study and Modification by the Duffy Antigen Variant. JAMA Cardiol. 2018:3(6):455-62.

22. Adatia I, Kothari SS, Feinstein JA. Pulmonary hypertension associated with congenital heart disease: pulmonary vascular disease: the global perspective. Chest. 2010;137(6 Suppl):52S-61S.

23. Alrddadi SM, Morsy MM, Albakri JK, Mohammed MA, Alnajjar GA, Fawaz MM, Alharbi AA, Alnajjar AA, Almutairi MM, Sayed AU, et al. Risk factors for prolonged mechanical ventilation after surgical repair of congenital heart disease. Experience from a single cardiac center. Saudi Med J. 2019;40(4):367-71.

24. Peñuelas O, Frutos-Vivar F, Fernández C, Anzueto A, Epstein SK, Apezteguía C, González M, Nin N, Raymondos K, Tomicic V, et al. Characteristics and outcomes of ventilated patients according to time to liberation from mechanical ventilation. Am J Respir Crit Care Med. 2011;184(4):430-7.

25. Faruk SO, Guzelmeric F, Yavuz Y, Akyuz M, Cevirme D, Tongut A, Ozbek $B$, Can HA, Ceyran H. The neutrophil lymphocyte ratio as a successful extubation predictor of prolonged intubation in pediatric heart surgery. Iran J Pediatriaqc. 2017;27:5.

26. Nydahl P, Ruhl AP, Bartoszek G, Dubb R, Filipovic S, Flohr HJ, Kaltwasser A, Mende $\mathrm{H}$, Rothaug $\mathrm{O}$, Schuchhardt D, et al. Early mobilization of mechanically ventilated patients: a 1-day point-prevalence study in Germany. Crit Care Med. 2014;42(5):1178-86.

\section{Publisher's Note}

Springer Nature remains neutral with regard to jurisdictional claims in published maps and institutional affiliations.
Ready to submit your research? Choose BMC and benefit from:

- fast, convenient online submission

- thorough peer review by experienced researchers in your field

- rapid publication on acceptance

- support for research data, including large and complex data types

- gold Open Access which fosters wider collaboration and increased citations

- maximum visibility for your research: over $100 \mathrm{M}$ website views per year

At BMC, research is always in progress.

Learn more biomedcentral.com/submissions 